\title{
Relationship between Helicobacter pylori infection and celiac disease: a cross-sectional study and a brief review of the literature
}

\author{
Sebahat Basyigit ${ }^{1}$, Oktay Unsal ${ }^{2}$, Metin Uzman ${ }^{3}$, Ferdane Sapmaz ${ }^{3}$, Ozlem Ceylan Dogan ${ }^{4}$, Ayse Kefeli ${ }^{5}$, \\ Zeliha Asilturk ${ }^{2}$, Abdullah Ozgur Yeniova ${ }^{6}$, Yasar Nazligul ${ }^{3}$ \\ ${ }^{1}$ Department of Gastroenterology, Artvin State Hospital, Artvin, Turkey \\ 2Department of Internal Medicine, Kecioren Research and Training Hospital, Ankara, Turkey \\ ${ }^{3}$ Department of Gastroenterology, Kecioren Research and Training Hospital, Ankara, Turkey \\ ${ }^{4}$ Department of Biochemistry, Kecioren Research and Training Hospital, Ankara, Turkey \\ ${ }^{5}$ Department of Gastroenterology, Siirt State Hospital, Siirt, Turkey \\ ${ }^{6}$ Department of Gastroenterology, Faculty of Medicine, Gaziosmanpasa University, Tokat, Turkey
}

Gastroenterology Rev 2017; 12 (1): 49-54

DOI: https://doi.org/10.5114/pg.2017.65681

Key words: immunoglobulin A, Helicobacter pylori, celiac disease.

Address for correspondence: Sebahat Basyigit MD, Department of Gastroenterology, Artvin State Hospital, Carsimh, 08000, Merkez, Artvin, Turkey, phone: +90 5056728160, e-mail: sbuyuktemiz@yahoo.com

\begin{abstract}
Introduction: Whether Helicobacter pylori triggers celiac disease $(C D)$ or protects against $C D$ is currently the subject of research. In the literature, there are epidemiologic studies that have reported conflicting results regarding the association between H. pylori and CD.

Aim: To compare the prevalence of CD autoantibody positivity and the levels of $C D$ autoantibodies between $H$. pylori-positive and $H$. pylori-negative subjects.

Material and methods: This study was prospectively designed and included 240 dyspeptic patients who underwent upper gastrointestinal endoscopy with gastric and duodenal biopsies. The patients were divided into two groups according to presence of H. pylori infection. The serum levels of immunoglobulin (Ig) A, tissue transglutaminase antibodies (tTGA; IgA and IgG classes), and anti-endomysial antibodies (EMA; IgA and IgG classes) were measured for all participants by a blinded biochemistry expert.

Results: There were no significant differences in the serum levels of CD autoantibodies or IgA between the two groups. There were also no significant differences in the percentages of subjects with positive CD serologies or subjects with IgA deficiencies between the groups.

Conclusions: Helicobacter pylori remains one of the bacterial species that is most likely to trigger autoimmunity. However, studies have failed to reveal a relationship between H. pylori and CD; thus, additional basic work on the immunological aspects of the microbial-host interactions and longitudinal studies enrolling patients at very early stages of the disease may help us to address this issue.
\end{abstract}

\section{Introduction}

Helicobacter pylori is a bacterium that can cause significant gastroduodenal diseases, including chronic gastritis, duodenal ulcers, and adenocarcinomas [1]. Helicobacter pylori is one of the rare infectious agents (along with Epstein-Barr virus) that have been suggested to be involved in several autoimmune disorders. Initially, this pathogen was considered to be associated with a type of autoimmune gastritis. Additionally, a large number of studies have attempted to associate $H$. pylori infection with the development of extra-gastrointestinal autoimmune disorders. Among these disorders, immune thrombocytopenic purpura, multiple sclerosis/neuromyelitis optica, autoimmune thyroid disease, and psoriasis, are well known [2].

Celiac disease $(C D)$ is a common autoimmune condition that affects the small bowel and is triggered by gluten in susceptible subjects. Although the pathogenesis of $C D$ has been well defined, the increasing prevalence of 
this disease had led to the consideration of a number of environmental risk factors that may trigger autoimmunity in the small bowel. Findings related to the timing of gluten ingestion and other infant feeding practices [3], rotavirus infections [4], and elective caesarean sections have led to suggestions that differential perinatal exposure to bacterial microbiota modulate the risk of CD [5].

A systemic humoral immune response and local immune inflammatory reactions are involved in both H. pylori infection and CD. In addition, it has been hypothesized that microbial exposure may affect the risk of $C D$, and chronic gastric infections that are capable of inducing duodenal ulcers and influencing the systemic immune responses may trigger autoimmunity in the small intestine. Thus, researchers have examined the association between $H$. pylori infection and CD. However, these authors have reported conflicting results. The majority of these studies have investigated the percentages of $H$. pylori positivity in CD patients [6-8]. The variability in the results is probably due to differences in the prevalence of $\mathrm{H}$. pylori infections among different populations and the identification of patients who are not yet exhibiting clinically overt CD.

\section{Aim}

In this study, we aimed to investigate whether the autoimmune response that is specific to $C D$ is triggered in $\mathrm{H}$. pylori infection. We compared the prevalences of $C D$ autoantibody positivity and the levels of CD autoantibodies between $H$. pylori-positive and $H$. pylori-negative subjects.

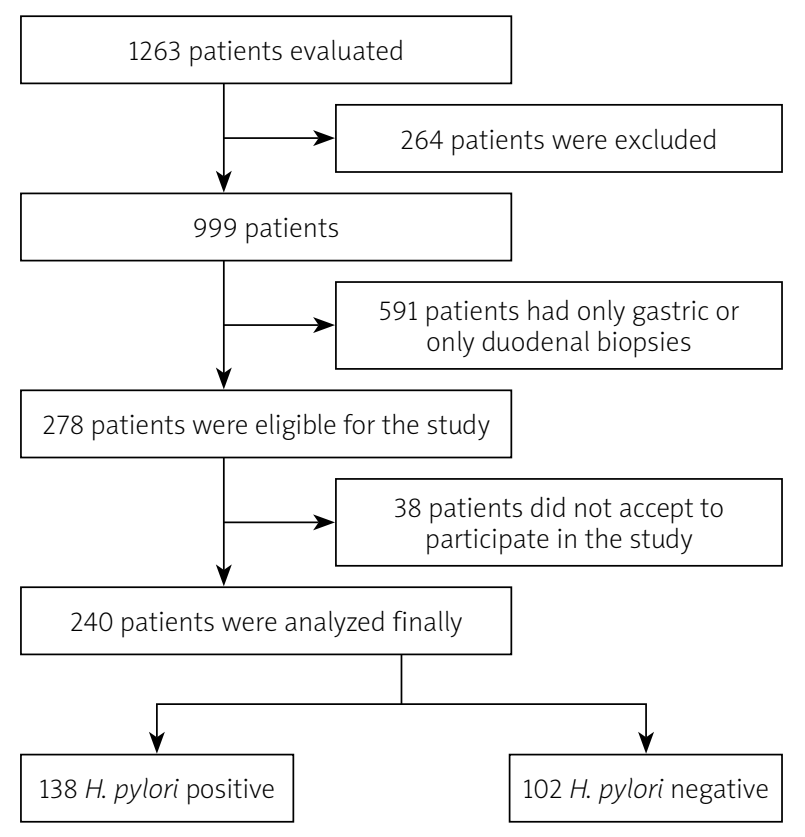

Figure 1. Schematic representation of the study

\section{Material and methods}

This cross-sectional study was conducted on dyspeptic patients who underwent upper gastrointestinal endoscopy with gastric and duodenal biopsies between January 1, 2014 and May 30, 2014 at a single center in Turkey. This study was approved by the institutional ethical board and was conducted in accordance with the Declaration of Helsinki. The subjects provided written informed consent to participate in the study and completed a standard questionnaire regarding their personal medical histories.

During the study period, a consecutive series of 1263 subjects between the ages of 18 and 75 years was evaluated. We excluded subjects with histories of histopathological diagnoses of any upper gastrointestinal malignancy (e.g., carcinoma or lymphoma, $n=22)$, gastric or duodenal surgery $(n=27)$, previously diagnosed $C D(n=15)$, other autoimmune diseases $(n=72)$, chronic infectious diseases including hepatitis B and hepatitis $C(n=128)$ and those with only gastric or only duodenal biopsies $(n=591)$. Patients who had previously received $H$. pylori eradication treatment were also excluded (230). Two hundred seventy-eight subjects were eligible for the study. A total of 240 patients agreed to participate in the study. The participation rate was $86.3 \%$ (Figure 1 ).

Blood samples were taken from the peripheral veins of the subjects on the day of the endoscopic procedure to assess the autoimmune markers of CD. The serum samples from the participants were separated and stored at $-80^{\circ} \mathrm{C}$ until the analyses, which were performed by a blinded biochemistry expert. Immunoglobulin (Ig) A and IgG classes of anti-endomysial antibodies (EMAs) were measured with enzyme-linked immunosorbent assays (ELISAs) (CeliAK EmA human IgG and IgA, Generic Assays (GA) GmbH, Dahlewitz, Germany). IgA and IgG classes of anti-tissue transglutaminase antibodies (tTGAs) were measured by ELISA (ImmuLisa, Immco, USA). The lower limits for positive results were defined as $20 \mathrm{U} / \mathrm{ml}$ for EMA and $20 \mathrm{EU} / \mathrm{ml}$ for tTGA. The total serum IgA values were measured with an immunoturbidimetric assay (Specialist Protein Analyzer (SPAplus) automatic analyzer, San Diego, USA). IgA deficiency was defined by an IgA level lower than $0.27 \mathrm{~g} / \mathrm{l}$.

The serum levels of liver enzymes, complete blood counts, endoscopic findings from the stomach and duodenum, histopathologic findings regarding the presence of $H$. pylori infection and the presence of intraepithelial lymphocytosis (IEL) with or without villous atrophy for the diagnosis of CD were also recorded from the medical reports. The participants were classified into two groups according to the presence of histopathologically diagnosed $H$. pylori infection. 


\section{Statistical analysis}

The statistical analyses were performed using the Statistical Package for the Social Sciences version 15.0 (SPSS, Chicago, IL, USA). The statistical results are presented as the means \pm the standard deviations, percentages or medians (minimum-maximum). We used Student's $t$ tests for normally distributed data. Mann-Whitney $U$ tests were used for the non-normally distributed data. The $\chi^{2}$ test was used to compare categorical variables between groups. The correlations between independent variables were analyzed with Pearson correlation tests. $P$-values under 0.05 were considered statistically significant.

\section{Results}

\section{Baseline characteristics of subjects}

A total of 1263 subjects were evaluated, and 278 subjects were eligible after excluding 985 subjects based on the exclusion criteria. Of these individuals, 240 subjects ( $86.3 \%$ participation rate) were included in the final analysis. The mean age of the enrolled subjects was $43.4 \pm 14.3$, and 127 (52.9\%) were female. A total of 138 (57.5\%) subjects had histopathologically diagnosed H. pylori infections, and a total of 12 (5\%) subjects had histopathologically and serologically diagnosed CD.

The baseline characteristics are summarized in Table I. Both the age and sex distributions of the two groups were similar. No significant differences regarding the levels of serum liver enzymes, complete blood counts, prevalence of presenting symptoms, or distributions of duodenal histopathological findings were identified. However, the prevalence of antral gastritis was significantly higher in the $H$. pylori-negative group compared with the H. pylori-positive group, and the prevalence of bulbitis was significantly higher in the $H$. pylori-positive group than the $H$. pylori-negative group.

The results of comparisons of the serum levels of CD autoantibodies and IgA between the two groups are presented in Table II. There were no significant differences in the serum levels of CD autoantibodies or IgA between the two groups. There were also no significant differences in the percentages of subjects with positive CD serologies or IgA deficiencies between the groups (Table II).

There were no statistically significant correlations between the serum levels of CD autoantibodies and the endoscopic findings.

\section{Discussion}

In the present study, we found no significant differences related to serum levels or positivity for $C D$ serologic markers between the $H$. pylori-positive and H. pylori-negative patients.
Table I. Comparison of clinical and demographic features between $H$. pylori positive and negative subjects

\begin{tabular}{|c|c|c|c|}
\hline Parameters & $\begin{array}{l}H . \text { pylori } \\
\text { positive } \\
(n=138)\end{array}$ & $\begin{array}{l}H . \text { pylori } \\
\text { negative } \\
(n=102)\end{array}$ & $P$-value \\
\hline Age [years] & $42.9 \pm 13.5$ & $43.8 \pm 15$ & 0.103 \\
\hline \multicolumn{4}{|l|}{ Gender, $n(\%)$ : } \\
\hline Female & $67(48.6)$ & $60(58.8)$ & \multirow[t]{2}{*}{0.074} \\
\hline Male & $71(51.4)$ & $42(41.2)$ & \\
\hline $\mathrm{Hb}[\mathrm{g} / \mathrm{dl}]^{*}$ & $14.3 \pm 2.1$ & $14.2 \pm 1.7$ & 0.080 \\
\hline WBC $\left[\times 10^{3} / \mu \mathrm{l}\right]^{\star}$ & $7374 \pm 1819$ & $7450 \pm 2058$ & 0.370 \\
\hline $\mathrm{PLT}\left[\times 10^{3} / \mu \mathrm{l}\right]^{*}$ & $254759 \pm 53733$ & $258444 \pm 59135$ & 0.790 \\
\hline $\mathrm{ALT}[\mathrm{IU} / \mathrm{I}]^{\star}$ & $21 \pm 14.7$ & $20.6 \pm 13.4$ & 0.971 \\
\hline AST [IU/I]* & $21.8 \pm 9$ & $21.3 \pm 7.8$ & 0.400 \\
\hline GGT [IU/I]* & $28.8 \pm 22$ & $26.3 \pm 15.7$ & 0.303 \\
\hline ALP $[I U / I]^{*}$ & $86.1 \pm 25.3$ & $83.3 \pm 26.3$ & 0.608 \\
\hline \multicolumn{4}{|c|}{ Symptoms, $n(\%)$ : } \\
\hline Bloating & $83(60.1)$ & $57(55.9)$ & \multirow[t]{3}{*}{0.298} \\
\hline Diarrhea & $8(5.8)$ & $10(9.8)$ & \\
\hline Weight loss & $20(14.5)$ & $16(15.7)$ & \\
\hline
\end{tabular}

\begin{tabular}{|c|c|c|c|}
\hline \multicolumn{4}{|c|}{ Endoscopic findings of stomach, $n(\%)$ : } \\
\hline Normal & $11(8)$ & $10(9.8)$ & 0.046 \\
\hline $\begin{array}{l}\text { Corpus dominant } \\
\text { gastritis }\end{array}$ & $4(2.9)$ & 0 & \\
\hline Antral gastritis & $88(63.8)$ & $72(70.6)$ & \\
\hline Pangastritis & $31(22.5)$ & $20(19.6)$ & \\
\hline Gastric ulcer & $4(2.9)$ & 0 & \\
\hline
\end{tabular}

Endoscopic findings of duodenum, $n$ (\%):

\begin{tabular}{lcc}
\hline Normal & $95(68.8)$ & $85(83.3)$ \\
\hline Bulbitis & $25(18.1)$ & $6(5.9)$ \\
\hline Duodenal ulcer & $13(9.4)$ & $4(3.9)$ \\
\hline Celiac disease & $5(3.6)$ & $7(6.9)$ \\
\hline
\end{tabular}

Histopathologic findings of duodenum, $n(\%)$ :

\begin{tabular}{|c|c|c|c|}
\hline Normal & $95(68.8)$ & 85 (83.3) & 0.255 \\
\hline IEL & 17 (12.3) & $7(6.9)$ & \\
\hline $\begin{array}{l}\text { Villus atrophy } \\
+ \text { IEL }\end{array}$ & $5(3.6)$ & $7(6.9)$ & \\
\hline
\end{tabular}

${ }^{*}$ Results are expressed as mean \pm SD or number and percentage. $\mathrm{Hb}$ - hemoglobin, WBC - white blood cell count, PLT - platelet count, ALT - alanine aminotransferase, AST - aspartate aminotransferase, GGT $\gamma$-glutamyltransferase, ALP - alkaline aminotransferase, IEL - intraepithelial lymphocytosis, Ig - immunoglobulin. 
Table II. Comparison of celiac disease serologic markers between $H$. pylori positive and negative subjects

\begin{tabular}{|c|c|c|c|}
\hline Parameters & $\begin{array}{l}\text { H. pylori } \\
\text { positive } \\
(n=138)\end{array}$ & $\begin{array}{l}H . \text { pylori } \\
\text { negative } \\
(n=102)\end{array}$ & $P$-value \\
\hline \multicolumn{4}{|l|}{ IgA: } \\
\hline Serum levels [mg/dl] & $\begin{array}{c}207 \\
(7-443)\end{array}$ & $\begin{array}{c}194 \\
(65-671)\end{array}$ & 0.581 \\
\hline Deficiency, $n$ (\%) & $7(2)$ & $2(5.1)$ & 0.128 \\
\hline \multicolumn{4}{|c|}{ Tissue transglutaminase IgA: } \\
\hline Serum level [EU/ml] & $\begin{array}{c}4.49 \\
(0.05-66.1)\end{array}$ & $\begin{array}{c}4.71 \\
(1.36-132.9)\end{array}$ & 0.080 \\
\hline Positivity, $n(\%)$ : & $5(3.9)$ & $4(3.6)$ & 0.581 \\
\hline \multicolumn{4}{|c|}{ Tissue transglutaminase IgG: } \\
\hline Serum level [EU/ml] & $\begin{array}{c}7.25 \\
(0.86-28.3) \\
\end{array}$ & $\begin{array}{c}6.36 \\
(0.98-168.9) \\
\end{array}$ & 0.779 \\
\hline Positivity, n (\%) & $4(2.9)$ & $7(6.9)$ & 0.128 \\
\hline \multicolumn{4}{|l|}{ Anti-endomysial IgA: } \\
\hline Serum level [EU/ml] & $\begin{array}{c}2.92 \\
(0.02-245.4) \\
\end{array}$ & $\begin{array}{c}2.5 \\
(0.01-166.9) \\
\end{array}$ & 0.500 \\
\hline Positivity, n (\%) & $3(2.2)$ & $4(3.9)$ & 0.366 \\
\hline \multicolumn{4}{|l|}{ Anti-endomysial IgG: } \\
\hline Serum level [EU/ml] & $\begin{array}{c}4.4 \\
(0.02-159) \\
\end{array}$ & $\begin{array}{c}3.8 \\
(0.02-150.5)\end{array}$ & 0.918 \\
\hline Positivity, n (\%) & $13(8.7)$ & $12(12.7)$ & 0.211 \\
\hline
\end{tabular}

Results are expressed as median (min-max) or number and percentage. $1 \mathrm{~g}-$ immunoglobulin.

Luminal factors trigger clinically overt CD in subjects with suitable combinations of host and environmental factors. Infectious agents are among the suspected environmental factors. Several mechanisms by which infectious agents may cause autoimmune disease have been proposed. These mechanisms include molecular mimicry, epitope spreading, the bystander effect, microbial super-antigens, immune complex formation, $\mathrm{MHC}$ class II expression on non-immune cells, direct inflammatory damage, high levels of pro-inflammatory cytokines such as interferon (IFN)- $\gamma$, and T-regulatory/Th17 imbalance [2].

Some histological evidence suggests a connection between $H$. pylori-related gastritis and $\operatorname{CD}[7,8]$. One of the earliest duodenal histopathologic findings in CD was an increase in IEL. This finding has also been observed in $40 \%$ of patients with $H$. pylori gastritis without any clinical or serological evidence of $C D$, and IEL can be reversed by the eradication of $H$. pylori [9]. However, while CD primarily affects the mucosal layer of the small intestine, inflammatory processes occur with a cascade of immune events and may not be limited to the small intestine. Supporting this phenomenon, $C D$ has been found to be frequently associated with abnormalities of gastric histology and gastric function, including gastritis, peptic ulcerations and atrophic gastritis [6]. Other works have also shown that lymphocytic gastritis is associated with $H$. pylori in CD patients [10, 11]. Gastric and duodenal pathologies are common in both $H$. pylori-related disorders and CD.

In contrast, there are some conflicting findings that are suggestive of a negative relationship between $H$. pylori infection and CD. The possibility of decreasing prevalence of $\mathrm{H}$. pylori infection with increasing incidence of $C D$ is thought provoking. Broide et al. also suggested that $H$. pylori infection and CD have different histopathological features. These authors reported that CD8+ IELs exist at significantly higher levels in CD patients than in $H$. pylori-infected patients without CD. These authors concluded that higher CD8+/CD4- IEL counts may be indicative of a $\mathrm{CD}$ diagnosis rather than $\mathrm{H}$. pylori gastritis [12]. T-regulatory lymphocytes that are recruited by $H$. pylori have systemic effects and specifically protect against allergic disorders. The down-regulation of the cellular responses mediated by T-regulatory cells in the bowel wall is diminished or lost in CD patients [13]. Thus, persons without $H$. pylori and without the recruited gastric T-regulatory cells may be less likely to down-regulate immune responses to gluten. Alternatively, $H$. pylori may affect ingested gluten through its modification of the gastric $\mathrm{pH}$ or via its proteases to reduce the immunogenicity of gluten [13].

Whether $H$. pylori triggers CD or protects against $C D$ is currently the subject of research. There are epidemiologic studies in the literature about the association between $H$. pylori and CD. However, these studies have reported conflicting results.

Initially, in 1992, Crabtree et al. found that there was no difference in the prevalence of $H$. pylori between patients with and without CD [14]. This finding was supported by further studies conducted by Luzza et al. in 1999 [15] and Aydogdu et al. in 2008 [7]. However, Diamanti et al. reported that patients with CD have a significantly lower prevalence of $H$. pylori infection compared with controls in 1999 [16]. Ciacci et al. from Italy [8] and Rostami Nejad et al. [17, 18] from Iran also found results similar to those of Diamanti et al. In addition, Villanacci et al. found that among patients with $\mathrm{CD}$, the presence of $\mathrm{H}$. pylori is associated with less severe degrees of villous atrophy [19]. In contrast, Konturek et al. from Germany reported that the prevalence of $H$. pylori infection is increased in CD patients and is associated with a lower prevalence of CagA-positive H. pylori strains [6]. This study provided the only data 
that demonstrate increased prevalence of $H$. pylori in patients with CD. These authors suggested that less virulent $H$. pylori strains may exacerbate the mucosal response in CD patients, whereas virulent $H$. pylori strains may be protective. Recently, based on a study with a large sample, Lebwohl et al. reported that the prevalence of $H$. pylori infection was lower in patients with CD compared to controls. These authors explained this result via the "hygiene hypothesis", which theorizes that decreased exposure to bacterial antigens may trigger autoimmunity. However, the results of these authors were obtained only in CD patients with villous atrophy. The prevalence of $H$. pylori was found to be significantly higher in patients with IEL in the same study [13].

The majority of these results regarding the prevalence of $H$. pylori positivity in patients with $C D$, and the variance in these results, may have been influenced by differences in the prevalence of $H$. pylori. In addition, the majority of $C D$ patients are underdiagnosed in some countries, and studies that have been conducted on patients with CD may not reflect the true prevalence. In individuals with $C D$, biopsies typically indicate villous atrophy, crypt hyperplasia and inflammation. However, some individuals with positive CD serologies have normal mucosa. Many of these individuals later develop $C D$, and the term "latent CD" is sometimes used when referring to such individuals [20]. In previous epidemiologic studies, patients with latent CD have also not been included. In atypical cases, autoantibodies, such as tTGAs, are very specific; hence, we could expect that $>95 \%$ of tTGA-positive cases might be gluten-sensitive [18]. In the present study, we investigated serologic markers of $C D$ in patients with $H$. pylori infections. Our study population reflected the general population in terms of the prevalence of $H$. pylori positivity, which was found to be $57.5 \%$ and similar to the results of previous studies conducted in Turkey [21, 22]. The prevalence of $C D$ has been reported to be nearly $0.5 \%$ in Turkey [23]. In our study, the prevalence of histopathologically diagnosed CD was found to be ten-fold higher than expected. This high prevalence might have resulted from the selection of only subjects who were admitted to the gastroenterology department and the accumulation of such patients in this specific department. Nevertheless, the prevalence of $C D$ was not different between the $H$. pylori-positive and $H$. pylori-negative subjects.

Our study had some limitations. Because $H$. pylori infection is the most common infection worldwide, our sample size was relatively small. However, our exclusion criteria were strict and limited the sample size. In addition, $H$. pylori may be a marker of other exposures, such as crowded living conditions, dietary habits, or not receiving antibiotics. These factors should be consid- ered in evaluations of the relationship between $H$. pylori infection and CD in further studies with larger samples.

\section{Conclusions}

Helicobacter pylori remains one of the bacterial species that is most likely to trigger autoimmunity. Although studies have failed to reveal a relationship between H. pylori and CD, additional basic work on immunological aspects of the microbe-host interactions and longitudinal studies that enroll patients in the very early stages of this disease may help us to address this issue.

\section{Conflict of interest}

The authors declare no conflict of interest.

\section{References}

1. Garza-González E, Perez-Perez GI, Maldonado-Garza HJ, et al. A review of Helicobacter pylori diagnosis, treatment, and methods to detect eradication. World J Gastroenterol 2014; 20: 1438-49.

2. Smyk DS, Koutsoumpas AL, Mytilinaiou MG, et al. Helicobacter pylori and autoimmune disease: cause or by stander. World J Gastroenterol 2014; 20: 613-29.

3. Ivarsson A, Persson LA, Nystrom L, et al. Epidemic of coeliac disease in Swedish children. Acta Paediatr 2000; 89: 165-71.

4. Stene LC, Honeyman MC, Hoffenberg EJ, et al. Rotavirus infection frequency and risk of celiac disease autoimmunity in early childhood: a longitudinal study. Am J Gastroenterol 2006; 101: 2333-40.

5. Marild K, Stephansson O, Montgomery S, et al. Pregnancy outcome and risk of celiac disease in offspring: a nationwide case-control study. Gastroenterology 2012; 142: 39-45.

6. Konturek PC, Karczewska E, Dieterich W, et al. Increased prevalence of Helicobacter pylori infection in patients with celiac disease. Am J Gastroenterol 2000; 95: 3682-3.

7. Aydogdu S, Cakir M, Yuksekkaya HA, et al. Helicobacter pylori infection in children with celiac disease. Scand J Gastroenterol 2008; 43: 1088-93.

8. Ciacci C, Squillante A, Rendina D, et al. Helicobacter pylori infection and peptic disease in coeliac disease. Eur J Gastroenterol Hepatol 2000; 12: 1283-7.

9. Memeo L, Jhang J, Hibshoosh H, et al. Duodenal intraepithelial lymphocytosis with normal villous architecture: common occurrence in $\mathrm{H}$. pylori gastritis. Modern Pathol 2005; 18: 1134-44.

10. Feeley KM, Heneghan MA, Stevens FM, et al. Lymphocytic gastritis and coeliac disease: evidence of a positive association. J Clin Pathol 1998; 51: 207-10.

11. Wolber R, Owen D, DelBuono L, et al. Lymphocytic gastritis in patients with celiac sprue or spruelike intestinal disease. Gastroenterology 1990; 98: 310-5.

12. Broide E, Sandbank J, Scapa E, et al. The immunohistochemistry profile of lymphocytic gastritis in celiac disease and Helicobacter pylori infection: interplay between infection and inflammation. Mediators Inflamm 2007; 2007: 81838. 
13. Lebwohl B, Blaser MJ, Ludvigsson JF, et al. Decreased risk of celiac disease in patients with Helicobacter pylori colonization. Am J Epidemiol 2013; 178: 1721-30.

14. Crabtree JE, O'Mahony S, Wyatt JI, et al. Helicobacter pylori serology in patients with coeliac disease and dermatitis herpetiformis. J Clin Pathol 1992; 45: 597-600.

15. Luzza F, Mancuso M, Imeneo M, et al. Helicobacter pylori infection in children with celiac disease: prevalence and clinicopathologic features. J Pediatr Gastr Nutr 1999; 28: 143-6.

16. Diamanti A, Maino C, Niveloni S, et al. Characterization of gastric mucosal lesions in patients with celiac disease: a prospective controlled study. Am J Gastroenterol 1999; 94: 1313-9.

17. Rostami-Nejad M, Villanacci V, Mashayakhi R, et al. Celiac disease and $\mathrm{Hp}$ infection association in Iran. Rev Esp Enferm Dig 2009; 101: 850-4.

18. Rostami Nejad M, Rostami K, Yamaoka Y, et al. Clinical and histological presentation of Helicobacter pylori and gluten related gastroenteropathy. Arch Iran Med 2011; 14: 115-8.

19. Villanacci V, Bassotti G, Liserre B, et al. Helicobacter pylori infection in patients with celiac disease. Am J Gastroenterol 2006; 101: 1880-5.

20. Ludvigsson JF, Brandt L, Montgomery SM. Symptoms and signs in individuals with serology positive for celiac disease but normal mucosa. BMC Gastroenterol 2009; 9: 57-66.

21. Sarı YS, Sander E, Erkan E, et al. Endoscopic diagnoses and CLO test results in 9239 cases, prevalence of Helicobacter pylori in Istanbul, Turkey. J Gastroenterol Hepatol 2007; 22: 1706-11.

22. Yucel T, Aygin D, Sen S, et al. The prevalence of Helicobacter pylori and related factors among university students in Turkey. Jpn J Infect Dis 2008; 61: 179-83.

23. Dalgic B, Sari S, Basturk B, et al. Prevalence of celiac disease in healthy Turkish school children. Am J Gastroenterology 2011; 106: 1512-7.

Received: 15.08 .2015

Accepted: 24.12.2015 